\section{Fatal air embolism}

To the Editor:

I commend Davies and Campbell for their work in reporting the three deaths and two cases of morbidity relating to dental implant surgery ${ }^{\prime}$ and Dr. R.L. Matthews for the excellent editorial in the same issue.

I would like to point out two inaccuracies in Davies' and Campbell's report. Citanest Forte is the proprietary name for prilocaine $\mathrm{HCl}$ four per cent with epinephrine $1 / 200,000$, not mepivicaine two per cent with levonordefrin $1 / 20,000$ as reported. ${ }^{2}$

The implication that "injection of catecholamines into the peridontal (sic) ligament is virtually the same as direct intravenous injection" cannot be found in the referenced paper. ${ }^{3}$ The paper by Lilienthal and Reynolds deals with intraosseous anaesthesia, and while injection into the bone may result in blood levels of catecholamines and anaesthetic agent comparable to that of an intravascular injection, ${ }^{4}$ this is not true of the periodontal ligament injection commonly employed for dental anaesthesia.

\section{K.J. Wright DMD}

3669 West 18th Avenue,

Vancouver, B.C.

V6S 1B3

\section{REFERENCES}

I Davies JM, Campbell LA. Fatal air embolism during dental implant surgery: a report of three cases. Can J Anaesth 1990; 37: 112-21.

2 Malamed SF. Handbook of Local Anesthesia. St. Louis: C.V. Mosby Company, 1980.

3 Lilienthal $B$, Reynolds $A K$. Cardiovascular responses to intraosscous injections containing catecholamines. Oral Surg Oral Med Oral Pathol 1975; 40: 574-83.

4 Allen GD. Dental Anesthesia and Analgesia. 3rd ed. Baltimore: Williams and Wilkins, 1984.

\section{REPLY}

We thank $D r$. Wright for his critical appraisal of our paper. He is correct concerning the proprietary name of one of the local anaesthetics used in the reported cases. Patient 2 received mepivacaine, the proprietary name of which is Carbocaine.

The paper by Lilienthal and Reynolds ${ }^{I}$ describes the cardiovascular response to the intraosseous (IO) injection of catecholamines and clearly demonstrates the "rapidity with which the catecholamines are absorbed into the general circulation." Dr. Wright is correct in stating that this paper does not refer directly to periodontal ligament (PDL) injection, a method of administering local anaesthetic "directly adjacent to a tooth to be anesthetized." However, the results are the same with either the 10 or PDL technique. Indeed, two papers on the subject of periodontal ligament injection equate this technique to that of intraosseous injection, on the basis of the spread of the injected solution and the systemic effects of the injectate. ${ }^{2.3}$ Periodontal ligament injection results in local anaesthetic being "distributed widely by passing through the cribiform plate and the medullary bone spaces and into the vascularure in and around the tooth and adjacent teeth." 2 Solutions injected by the PDL technique are rapidly absorbed into the systemic circulation, and the results are similar, "whether the injections were done intravenously, intraosseously or periodontally." Smith and Walton also state that the "name of the technique refers to the intended site of needle insertion and not to the path or spread of the injected solution... In reality, the periodontal ligament injection is an intraosseous injection."

J.M. Davies MSc MD FRCPC

Department of Anaesthesia

Foothills Hospital at the University of Calgary

Calgary, Alberta T2N 2T9

Linda A. Campbell RN

Medical Investigations

Office of the Chief Coroner of British Columbia

Burnaby, British Columbia

\section{REFERENCES}

1 Lilienthal B, Reynolds $A K$. Cardiovascular responses to intraosseous injections containing catecholamincs. Oral Surg Oral Med Oral Pathol 1975; 40: 574-83.

2 Smith $G N$, Walton RE. Periodontal ligament injection: distribution of injection solutions. Oral Med Oral Surg Oral Pathol 1983; 55: 232-8.

3 Smith GN, Pashley $D H$. Periodontal ligament injection: evaluation of systemic effects. Oral Surg Oral Med Oral Pathol 1983; 56: 571-4.

\section{Massive tongue swelling after uncomplicated general anaesthesia}

\section{To the Editor:}

We present a case of an uncomplicated general anaesthetic requiring postoperative tracheal intubation due to massive tongue swelling possibly due to the glutaraldehyde solution used for sterilization.

A 67-yr-old man, following removal and debridement of infected components of a left total knee arthroplasty under uncomplicated general anaesthesia, presented for a second debridement. The patient weighed $104 \mathrm{~kg}$ and had a 25 pack-year history of cigarette smoking. His medical history included hypertension, exertional angina relieved by sublingual nitroglycerin, and well-controlled psoriasis. He had had an anaphylactic reaction to penicillin ten years ago which required tracheal intubation. His medication included metoprolol, furosemide, captopril, and cefotaxime. 